\title{
KEANEKARAGAMAN JENIS SEMUT (Formicidae) DI HUTAN KOTA KABUPATEN KETAPANG KALIMANTAN BARAT
}

\author{
(Species Diversity Of Ant (Formicidae) in Ketapang City District Forest, West Kalimantan)
}

\author{
Adi Mustika, Hari Prayogo, M. Sofwan Anwari \\ Fakultas Kehutanan Universitas Tanjungpura Jalan Daya Nasional Pontianak 78124 \\ E-mail: adimustika922@gmail.com
}

\begin{abstract}
The diversity of ant species is one of the links in ecosystem stability as decomposing insects as well as food sources so that its existence becomes very ecologically important. Information about the types of ants found in the urban forest of Ketapang Regency is not yet available, therefore the problem of this research is how the diversity of ant species (Formicidae) in the urban forest of Ketapang Regency. This study aims to document the richness and diversity of ant species in the urban forest of Ketapang Regency, West Kalimantan. The method used was purposive sampling and systematic where the placement of traps was carried out according to the presence of ants in terrestrial and arboreal types in secondary forest habitats. Based on the results of research in the urban forest of Ketapang Regency, which was carried out in two types, namely terrestrial type and arboreal type, 10 species of 5 sub-families were found. Sub-families and types of ants found include: Dolichoderinae (Dolichoderus burmanicus, Dolichoderus taprobanae ceramensis), Formicinae (Aphomomyrmex afer, Polirachis browni, Prenolepis fisheri, Chepalotes femoral), Myrmicinae (Crematogester yameni, Crematogester indet), Ponerinae (Odontomachus haematodus), Pseudomyrmecinae (Tetraponera attenuata). The species diversity index $\left(\mathrm{H}^{\prime}\right)$ in terrestrial type secondary forest habitat $\left(\mathrm{H}^{\prime}=0.62\right)$ and arboreal type $\left(\mathrm{H}^{\prime}=0.81\right)$, the results of the two types in the secondary forest can be concluded that it is still relatively low.
\end{abstract}

Keywords: Ants, Secondary forest habitat, Species diversity

\section{PENDAHULUAN}

Semut (Formicidae) merupakan salah satu kelompok serangga yang keberadaannya sangat umum dan hampir menyebar luas. Semut merupakan serangga paling sukses dari kelompok serangga lainnya, terdapat dimana-mana di habitat terestrial dan jumlahnya melebihi hewan-hewan darat lainnya. Keberadaannya dimulai dari kutub sampai tropis dan daerah pesisir sampai pegunungan (Borror et al., 1992).

Hutan kota Kabupaten Ketapang merupakan suatu kawasan dalam atau pinggiran kota yang di dominasi oleh pepohonan yang tumbuh, terdapat beranekaragam jenis flora dan fauna yang memiliki kondisi alami dan dihuni oleh berbagai macam jenis semut. Keberadaan semut di hutan kota ini sangat erat kaitannya dengan keberadaan berbagai jenis tumbuhan, hewan, dan lingkungan yang ada di hutan kota ini. Pengetahuan tentang jenis semut merupakan informasi yang penting bagi kelestarian jenis tumbuhan dan hewan serta kelestarian alam yang berada di hutan kota Kabupaten Ketapang.

Keberagaman jenis semut merupakan salah satu mata rantai di dalam kestabilan 
ekosistem sebagai serangga pengurai maupun sebagai sumber makanan sehingga keberadaannya menjadi sangat penting secara ekologis. Informasi tentang jenis semut yang terdapat di hutan kota Kabupaten Ketapang belum tersedia, oleh karena itu masalah penelitian ini adalah bagaimana keberagaman jenis semut (Formicidae) di hutan kota Kabupaten Ketapang. Penelitian ini bertujuan untuk mendokumentasikan kekayaan dan keragaman jenis semut (Formicidae) di hutan kota Kabupaten Ketapang.

\section{METODE PENELITIAN}

\section{Tempat dan Waktu Penelitian}

Penelitian ini dilaksanakan di Hutan Kota Kabupaten Ketapang Kalimantan Barat. Penelitian dilakukan dari tanggal 1 28 Agustus 2017 dan dilanjutkan dengan mengidentifikasi jenis semut dan analisis data.

\section{Penempatan Jalur Pengamatan}

Jalur pengamatan ditetapkan berdasarkan pertimbangan-pertimbangan dengan memperhatikan kondisi fisik dan biologis yang mempengaruhi keberadaan semut di lapangan, dengan demikian peletakkan jebakan dilakukan secara sengaja (purposive sampling) dan sistematis pada jebakan Pitfall Trap. Jalur pengamatan ditempatkan pada hutan sekunder di dalam hutan kota dengan peletakan setiap jebakan terdiri dari permukaan tanah, bagian tengah pohon, dan atas pohon. Adapun penempatan jebakan yang akan digunakan dalam setiap jalur, antara lain :

- bagian permukaan tanah menggunakan jebakan jatuh berumpan (Pitfall Trap)
- bagian tengah pohon menggunakan perangkap kertas berperekat (Fly sheet), dan

- bagian atas pohon menggunakan perangkap kertas berperekat (Fly sheet).

Jalur pengamatan di buat sebanyak 4 jalur berdasarkan kondisi lokasi penelitian. Panjang setiap jalur $100 \mathrm{~m}$, dan jarak antara jalur ke jalur $50 \mathrm{~m}$. Setiap jalur memiliki 10 buah jebakan jatuh berumpan (Pitfall Trap) dan perangkap kertas berperekat (Fly sheet) masing-masing pada bagian tengah pohon 10 buah dan pada bagian atas pohon 10 buah dengan memilih pohon terdekat dalam jalur. Pemasangan perangkap dimulai pada jam 07.00 WIB dan diganti dengan perangkap baru pada jam 17.00 WIB, sehingga didapat data semut dari jam $07.00-17.00$ WIB dan jam 17.00 - 07.00 WIB.

\section{Analisis Data}

1. Analisis Data Keanekaragaman Jenis

a. Indeks Keanekaragaman Jenis ( $H^{\prime}$ (Sannon-Wiener))

$H$ ' merupakan nilai untuk mengetahui keanekaragaman jenis berdasarkan kelimpahan jenisnya.

Rumus :

$$
\mathrm{H}^{\prime}=-\sum P i \operatorname{In} P i
$$

Diketahui :

$P i=$ Nilai kelimpahan semut

$H^{\prime}=$ Keanekaragaman jenis

$$
P i=\frac{n i}{N}
$$

Diketahui :

$n i=$ Jumlah individu suatu jenis ke- $i$

dalam jalur

$N=$ Total jumlah individu dalam jalur 
b. Indeks Kekayaan Jenis (d)

Perhitungan ini dimaksudkan untuk mengetahui pola penyebaran jenis dari suatu komunitas.

Rumus : $\quad \mathrm{d}=\frac{S-1}{\operatorname{In} N}$

Diketahui :

$S=$ Jumlah jenis

$N=$ Jumlah individu seluruh jenis

c. Indeks Similaritas (IS)

IS dihitung dengan rumus Similaritas Jaccards dengan rumus :

$$
\mathrm{IS}=\frac{C}{A+B+C} \times 100 \%
$$

Di mana :
$A=$ Jumlah jenis yang hanya

dijumpai pada stasiun I

$B=$ Jumlah jenis yang hanya terdapat pada stasiun II

$C=$ Jumlah jenis yang terdapat pada stasiun I dan II

\section{HASIL DAN PEMBAHASAN}

Berdasarkan hasil penelitian di hutan kota Kabupaten Ketapang yang dilakukan pada dua tipe yaitu terestrial dan arboreal ditemukan sebanyak 10 spesies dari 5 sub famili dengan jumlah total 4.448 individu. Jumlah individu semut terestrial dan arboreal yang ditemukan di lokasi penelitian dapat di lihat pada Tabel 2.

Tabel 1. Jumlah Individu Semut Tipe Terestrial dan Tipe Arboreal di Habitat Hutan Sekunder (Number of Terrestrial Type Ants and Arboreal Types in Secondary Forest Habitats)

\begin{tabular}{|c|c|c|c|c|}
\hline \multirow[b]{2}{*}{ No } & \multirow[b]{2}{*}{ Sub Famili } & \multirow[b]{2}{*}{ Spesies } & \multicolumn{2}{|c|}{ Hutan Sekunder } \\
\hline & & & $\begin{array}{l}\text { Terestrial } \\
\text { (individu) }\end{array}$ & $\begin{array}{r}\text { Arboreal } \\
\text { (individu) }\end{array}$ \\
\hline 1 & \multirow{2}{*}{ Dolichoderinae } & Dolichoderus burmanicus & 426 & 536 \\
\hline 2 & & D. taprobanae ceramensis & 295 & 298 \\
\hline 3 & \multirow{3}{*}{ Formicinae } & Aphomomyrmex afer & & 399 \\
\hline 4 & & Polirhachis browni & & 191 \\
\hline 5 & & Prenolepis fisheri & 528 & \\
\hline 6 & \multirow{3}{*}{ Myrmicinae } & Chepalotes femoralis & 121 & \\
\hline 7 & & Crematogester yameni & & 283 \\
\hline 8 & & Crematogester indet & & 644 \\
\hline 9 & Ponerinae & Odontomachus haematodus & 310 & \\
\hline 10 & Pseudomyrmecinae & Tetraponera attenuate & & 417 \\
\hline & & & 1.680 & 2.768 \\
\hline
\end{tabular}

Dominasi jenis semut yang banyak di temukan pada hutan sekunder setiap Jalur pada dua tipe yaitu :

a. Terestrial

Jalur I dengan dominasi jumlah yang banyak didapat yaitu jenis Prenolepis fisheri dengan jumlah 199 individu dan yang kedua Dolichoderus burmanicus dengan jumlah jenis 138 individu. Sedangkan yang paling sedikit didapat adalah jenis Cephalotes femoralis dengan jumlah 40 individu. Jalur II dengan jumlah yang banyak didapat yaitu Prenolepis fisheri dengan jumlah 154 individu dan yang kedua Dolichoderus taprobane ceramensisis dengan jumlah 102 individu. Sedangkan yang paling sedikit adalah Cephalotes femoralis dengan jumlah 34 individu. Jalur III dengan jumlah yang banyak didapat yaitu Prenolepis fisheri dengan jumlah 108 individu dan yang kedua 
Dolichoderus burmanicus dengan jumlah 97 individu. Sedangkan yang paling sedikit adalah Cephalotes femoralis dengan jumlah 30 individu. Jalur IV dengan jumlah yang banyak didapat yaitu Dolichoderus burmanicus dengan jumlah 132 individu dan yang kedua Odontomachus haematodus dengan jumlah 82 individu. Sedangkan yang paling sedikit adalah Cephalotes femoralis dengan jumlah 17 individu.

b. Arboreal

Jalur I dengan dominasi jumlah yang banyak didapat yaitu jenis Crematogester indet dengan jumlah 192 individu dan yang kedua Tetraponera attenuata dengan jumlah jenis 185 individu, sedangkan yang paling sedikit didapat adalah jenis Aphomomyrmex afer dengan jumlah 78 individu. Jalur II dengan jumlah yang banyak didapat

Tabel 2. Jumlah Individu Semut Tiap Jalur di Habitat Hutan Sekunder Tipe Terestrial dan Tipe Arboreal (Number of Individual Ants in Each Track in Terrestrial Type Secondary Forest Habitats and Arboreal Type)

\begin{tabular}{|c|c|c|c|c|c|c|c|c|c|c|}
\hline \multirow{3}{*}{ No } & \multirow{3}{*}{ Sub Famili } & \multirow{3}{*}{ Spesies } & \multicolumn{8}{|c|}{ Hutan Sekunder } \\
\hline & & & \multicolumn{4}{|c|}{$\begin{array}{l}\text { Terestrial } \\
\text { (Jalur) }\end{array}$} & \multicolumn{4}{|c|}{$\begin{array}{l}\text { Arboreal } \\
\text { (Jalur) }\end{array}$} \\
\hline & & & $\mathrm{I}$ & II & III & IV & $\mathrm{I}$ & II & III & IV \\
\hline 1 & \multirow{2}{*}{ Dolichoderinae } & Dolichoderus burmanicus & 138 & 59 & 97 & 132 & 158 & 126 & 139 & 113 \\
\hline 2 & & D. taprobanae ceramensis & 41 & 102 & 77 & 75 & 132 & 67 & 75 & 24 \\
\hline 3 & \multirow{4}{*}{ Formicinae } & Aphomomyrmex afer & - & - & - & - & 78 & 139 & 109 & 73 \\
\hline 4 & & Polyrhachis browni & - & - & - & - & - & 56 & 114 & 21 \\
\hline 5 & & Prenolepis fisheri & 199 & 154 & 108 & 67 & - & - & - & - \\
\hline 6 & & Cephalotes femoralis & 40 & 34 & 30 & 17 & - & - & - & - \\
\hline 7 & \multirow[t]{2}{*}{ Myrmicinae } & Crematogester yameni & - & - & - & - & 8 & 113 & 48 & 114 \\
\hline 8 & & Crematogester indet & - & - & - & - & 192 & 264 & 80 & 108 \\
\hline 9 & Ponerinae & Odontomachus haematodus & 80 & 94 & 54 & 82 & - & - & - & - \\
\hline 10 & Pseudomyrmecinae & Tetraponera attenuate & - & - & - & - & 185 & 88 & 58 & 86 \\
\hline
\end{tabular}

\section{Indeks Keanekaragaman Jenis (H')}

Hasil perhitungan indeks keanekaragaman jenis (H') semut di hutan kota Kabupaten Ketapang tipe yaitu Crematogester indet dengan jumlah 264 individu dan yang kedua Aphomomyrmex afer dengan jumlah 139 individu. Sedangkan yang paling sedikit adalah Polyrachis browni dengan jumlah 56 individu. Jalur III dengan jumlah yang banyak didapat yaitu Dolichoderus burmanicus dengan jumlah 139 individu dan yang kedua Polyrachis browni dengan jumlah 114 individu. Sedangkan yang paling sedikit adalah Crematogester yameni dengan jumlah 48 individu. Jalur IV dengan jumlah yang banyak didapat yaitu Crematogester yameni dengan jumlah 114 individu dan yang kedua Polichoderus burmanicus dengan jumlah 113 individu. Sedangkan yang paling sedikit adalah Polyrachis browni dengan jumlah 21 individu. 
Tabel 3. Indeks Keanekaragaman Jenis (H') Semut Tipe Terestrial dan Tipe Arboreal (Terrestrial Type and Arboreal Type Diversity Index $\left(H^{\prime}\right)$ Type Ants)

\begin{tabular}{cc}
\hline Hutan Sekunder & Indeks Keragaman $\left(\mathrm{H}^{\prime}\right)$ \\
\hline Terestrial & 0,623 \\
Arboreal & 0,812 \\
\hline
\end{tabular}

Keanekaragaman jenis semut terestrial dan arboreal pada habitat hutan sekunder memiliki perbedaan. Pada habitat tipe terestrial lebih rendah yaitu sebear 0,623 daripada habitat tipe arboreal yang mempunyai nilai indeks keanekaragaman sebesar 0,812 . Hal ini di sebabkan karena permukaan tanah sering mengalami genangan air yang terjadi pada pasang surut air, sehingga habitat hutan sekunder tersebut lebih dominan pada tipe arboreal.

Nilai indeks keanekaragaman dari kedua habitat tersebut masih tergolong rendah karena menurut Riyanto (2007)

Tabel 4. Indeks Kekayaan Jenis (d) di Habitat Hutan Sekunder Tipe Terestrial dan Tipe Arboreal (Type Wealth Index (d) in Terrestrial Type Secondary Forest Habitats and Arboreal Types)

\begin{tabular}{cc}
\hline Hutan Sekunder & Indeks Kekayaan Jenis (d) \\
\hline Terestrial & 1,240 \\
Arboreal & 1,743
\end{tabular}

Kekayaan jenis berbanding lurus dengan nilai keanekaragaman jenis dan sangat ditentukan oleh jumlah jenis penyusun vegetasi, dengan bertambahnya jenis maka nilai kekayaan jenis dan keanekaragaman jenis juga akan meningkat. Dari hasi analisis data, nilai kekayaan jenis tertinggi terdapat pada habitat hutan sekunder tipe arboreal dengan nilai sebesar 1,743 .

Indeks Similaritas (IS)/Koefisien Kesamaan

Hasil perhitungan koefisien kesamaan (IS) semut di hutan kota Kabupaten Ketapang pada habitat hutan sekunder tipe terstrial dan tipe arboreal dapat dilihat pada Tabel 5.

Tabel 5. Indeks Similaritas (IS)/Koefisien Kesamaan Pada Habitat Hutan Sekunder Tipe Terestrial dan Tipe Arboreal (Similarity Index (IS) / Coefficient of Similarity to Terrestrial Type Secondary Forest Habitats and Arboreal Types) 
$\begin{array}{ccc}\text { Koefisien } & \begin{array}{c}\text { kesamaan } \\ \text { besarnya }\end{array} & \begin{array}{r}\text { kesamitas } \\ \text { menunjukkan }\end{array} \\ \text { komunitas yang dibandingkan. Menurut }\end{array}$ Odum (1996) menyatakan bahwa kisaran indeks kesamaan jenis antara 80 - $100 \%$ dianggap sama, $50-80 \%$ dianggap berbeda, dan $<50 \%$ dianggap berbeda nyata. Hal ini disebabkan karena komunitas tidak hanya mempunyai kesatuan fungsional tertentu, tetapi juga mempunyai kesatuan komposisi dimana terdapat peluang bahwa jenis tertentu akan hidup berdampingan. Meskipun demikian jenis-jenis tersebut sebagian besar dapat diganti, sehingga secara fungsional komunitas yang serupa dapat memiliki komposisi yang berbeda.

Hasil penelitian dapat diketahui bahwa jenis yang sama yang ditemukan pada habitat hutan sekunder tipe terestrial dan tipe arboreal adalah Dolichoderus burmanicus dan Dolichoderus taprobane ceramensis dengan sub famili Dolichederinae dan satu genus Dolichoderus. Jenis spesies semut ini dengan hasil yang di dapatkan di dalam jalur pengamatan, ditemukan beberapa diantara jebakan dan perangkap sehingga keberadaan dan aktivitasnya ada di terestrial (permukaan tanah) dan ada juga di arboreal (di atas pohon).

\section{Kelembaban dan Suhu}

Kelembaban dan suhu udara di hutan kota Kabupaten Ketapang yang di dapat dari hasil pengukuran dengan nilai rata-rata rekapitulasi dapat dilihat pada Tabel 6.

Tabel 6. Nilai Rata-rata Kelembaban dan Suhu di Lokasi Penelitian (Value of Average Humidity and Temperature at the Research Location)

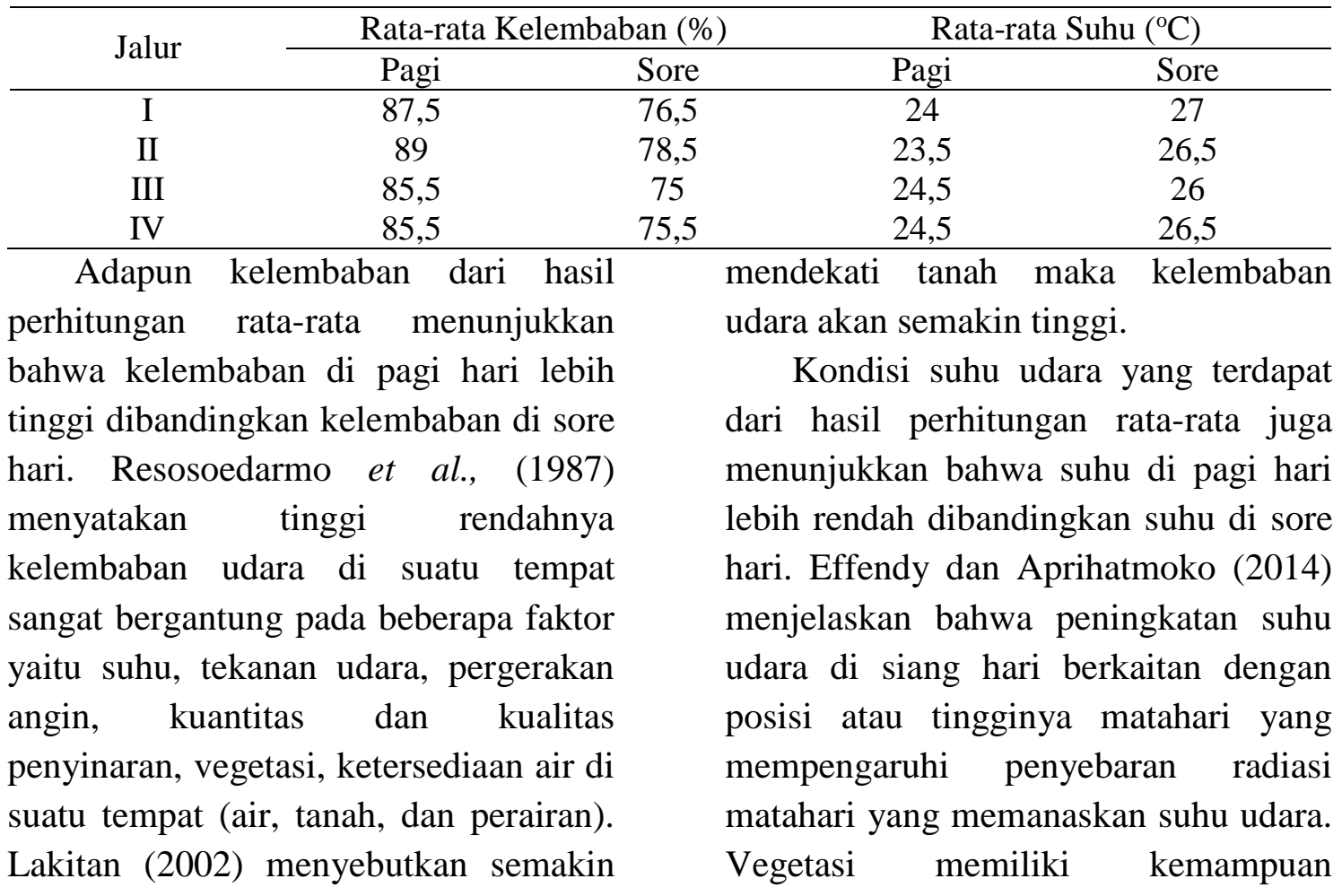


mengurangi peningkatan suhu karena menyerap radiasi matahari yang tinggi (Zahra, 2014)

\section{KESIMPULAN}

1. Pada habitat hutan sekunder tipe terestrial ditemukan 4 sub famili yang terdiri dari 5 spesies dengan jumlah seluruh individu yaitu 1.680 individu, sedangkan pada tipe arboreal ditemukan populasi dengan jumlah 2.768 individu yang terdiri dari 4 subfamili dan 7 spesies. Jumlah individu pada habitat hutan sekunder tipe arboreal lebih besar dibandingkan dengan tipe terestrial, hal ini disebabkan oleh faktor permukaan tanah sering mengalami genangan air yang terjadi pada pasang surut air, sehingga habitat hutan sekunder tersebut lebih dominan pada tipe arboreal.

2. Indeks keanekaragaman jenis semut di kedua lokasi adalah kurang dari 1 , sehingga bisa disebut nilai keanekaragaman semut di lokasi ini rendah.

\section{DAFTAR PUSTAKA}

Borror DJ, Donal, De LM, Dwight, Triplehorn CA. 1992. Pengenalan Pelajaran Serangga. Gadjah Mada University Press, Yogyakarta.

Effendy S. dan Aprihatmoko F. 2014. Kaitan RTH Dengan Kenyamanan Termal Perkotaan. Jurnal Agromet, 28 (1): 23-32

Lakitan B. 2002. Dasar-dasar Klimatologi. PT Raja Grafindo Persada, Jakarta

Odum EP. 1996. Dasar-dasar Ekologi. Edisi ke-3. Samingan T.
(Penerjemah), Yogyakarta (ID): Gadjah Mada University Press.

Resosoedarmo RK, Kartawinata K, Soegiarto A. 1987. Pengantar Ekologi. Remaja Karya, Bandung

Riyanto. 2007. Kepadatan, Pola Distribusi dan Peranan Semut Pada Tanaman di Sekitar Lingkungan Tempat Tinggal. Jurnal Penelitian Sains ; 10 (2) : 241-253.

Zahra AF. 2014. Evaluasi Keindahan dan Kenyamanan RTH Alun-alun Kota Batu. Jurnal Produksi Tanaman ; 7 (2) : 57-66 